\title{
Miamiensis avidus (Ciliophora: Scuticociliatida) causes systemic infection of olive flounder Paralichthys olivaceus and is a senior synonym of Philasterides dicentrarchi
}

\author{
Sung-Ju Jung*, Shin-Ichi Kitamura, Jun-Young Song, Myung-Joo Oh \\ Department of Aqualife Medicine, Chonnam National University, Chonnam 550-749, Korea
}

\begin{abstract}
The scuticociliate Miamiensis avidus was isolated from olive flounder Paralichthys olivaceus showing typical symptoms of ulceration and hemorrhages in skeletal muscle and fins. In an infection experiment, olive flounder (mean length: $14.9 \mathrm{~cm}$; mean weight: $26.8 \mathrm{~g}$ ) were immersion challenged with $2.0 \times 10^{3}, 2.0 \times 10^{4}$ and $2.0 \times 10^{5}$ ciliates $\mathrm{ml}^{-1}$ of the cloned YS1 strain of M. avidus. Cumulative mortalities were $85 \%$ in the $2.0 \times 10^{3}$ cells ml$^{-1}$ treatment group and $100 \%$ in the other 2 infection groups. Many ciliates, containing red blood cells in the cytoplasm, were observed in the gills, skeletal muscle, skin, fins and brains of infected fish, which showed accompanying hemorrhagic and necrotic lesions. Ciliates were also observed in the lamina propria of the digestive tract, pharynx and cornea. The fixed ciliates were $31.5 \pm 3.87 \mu \mathrm{m}$ in length and $18.5 \pm 3.04 \mu \mathrm{m}$ in width, and were ovoid and slightly elongated in shape, with a pointed anterior and a rounded posterior, presenting a caudal cilium. Other morphological characteristics were as follows: 13 to 14 somatic kineties, oral ciliature comprising membranelles M1, M2, M3, and paroral membranes PM1 and PM2, contractile vacuole at the posterior end of kinety 2 , shortened last somatic kinety and a buccal field to body length ratio of $0.47 \pm 0.03$. In addition, continuous PM1 and PM2, lack of M3 and variable kinetosome numbers in M2 and M3 were frequently observed. Specimens in the current study were compared with previous reports on $M$. avidus and Philasterides dicentrarchi and confirmed consistently that these 2 taxa are conspecific.
\end{abstract}

KEY WORDS: Miamiensis avidus - Philasterides dicentrarchi - Ciliophora - Scuticociliatida · Pathogenicity . Olive flounder

\section{INTRODUCTION}

Marine ciliates belonging to the order Scuticociliatida are histophagous opportunistic parasites that occur in cultured fish worldwide. Philasterides dicentrarchi in sea bass Dicentrachus labrax, turbot Scophthalmus maximus and olive flounder Paralichthys olivaceus (Dragesco et al. 1995, Iglesias et al. 2001, Kim et al. 2004a), Uronema nigricans in southern bluefin tuna Thunnus maccoyii (Munday et al. 1997), Uronema-like ciliates in turbot (Sterud et al. 2000) and Tetrahymena corlissi in guppy Poecilia reticulata (Imai et al. 2000) have been recognized in diseased fishes. Mortality by infection with unidentified scuticociliate
(Yoshinaga \& Nakazoe 1993), Uronema marinum (Jee et al. 2001), Pseudocohnilembus persalinus (Kim et al. 2004b), Philasterides dicentrarchi (Kim et al. 2004a) and Miamiensis avidus (Jung et al. 2005) has been reported in farmed olive flounder.

In a previous study, 8 strains of scuticociliates isolated from olive flounder exhibited the same small subunit ribosomal RNA (SSU rRNA), and were identified as Miamiensis avidus (Jung et al. 2005). As a result, we hypothesized that $M$. avidus is an important pathogen of olive flounder in Korean coastal waters. In the present study, we describe the pathogenicity of $M$. avidus in olive flounder, as well as the pathological changes that occur in experimentally infected fish. We also 
describe, the morphometric characteristics of $M$. avidus cultured in Chinook salmon embryo (CHSE214) cells and confirm $M$. avidus as a senior synonym for Philasterides dicentrarchi.

\section{MATERIALS AND METHODS}

Naturally infected fish. Wet preparations of skeletal muscle, gills and brain from Paralichthys olivaceus olive flounder showing typical symptoms of infection (ulceration and hemorrhage of skeletal muscle) were examined for the presence of ciliates. Small fish were fixed whole, in Bouin's solution; in the case of larger specimens, skeletal muscle, gills, liver, kidney, spleen, heart and brain were fixed in $10 \%$ formalin solution.

Experimental infection. A cloned strain of Miamiensis avidus, YS1, was cultured for $6 \mathrm{~d}$ in CHSE-214 cells, then collected and centrifuged at $980 \times g$ for $5 \mathrm{~min}$. The ciliates were suspended in PBS (phosphate-buffered saline), and numbers were estimated using a hemocytometer. Olive flounder (mean total length: $14.9 \mathrm{~cm}$; mean body weight: $26.8 \mathrm{~g}$ ) were kept in an indoor tank for $2 \mathrm{wk}$ prior to ciliate infection. Three groups of 20 fish were exposed to the ciliates for $45 \mathrm{~min}$ in $4 \mathrm{l}$ of aerated water containing $2.0 \times 10^{3}, 2.0 \times 10^{4}$, or $2.0 \times 10^{5}$ ciliates $\mathrm{ml}^{-1}$. A control group of 20 fish was treated similarly, without exposure to ciliates. The seawater volume was then increased to $20 \mathrm{l}$ for each treatment group, the aquaria were shielded from sunlight by black vinyl sheeting, and the water temperature was maintained at 17 to $18^{\circ} \mathrm{C}$. Dead and moribund fish were collected, and their gills and skin were subjected to histopathological examination.

Histological examination. Fixed samples were dehydrated through an ethanol series, embedded in paraffin and sliced into $4 \mu \mathrm{m}$ sections. The sections were then stained with hematoxylin and eosin.

Morphology of ciliates. Ciliates were isolated aseptically from the brains of infected fish and cultured in CHSE-214 cells in a $25 \mathrm{~cm}^{2}$ tissue culture flask, as described by Jung et al. (2005). The YS1 strain isolated in May 1999 in the Yosu area was selected for morphological identification. The ciliates were stained using the silver carbonate and 'wet' silver nitrate methods described by Foissner (1991).

\section{RESULTS}

\section{Experimental infection}

Experimentally infected Paralichthys olivaceus olive flounder resembled those that were naturally infected. Ulcers and hemorrhages were observed around the

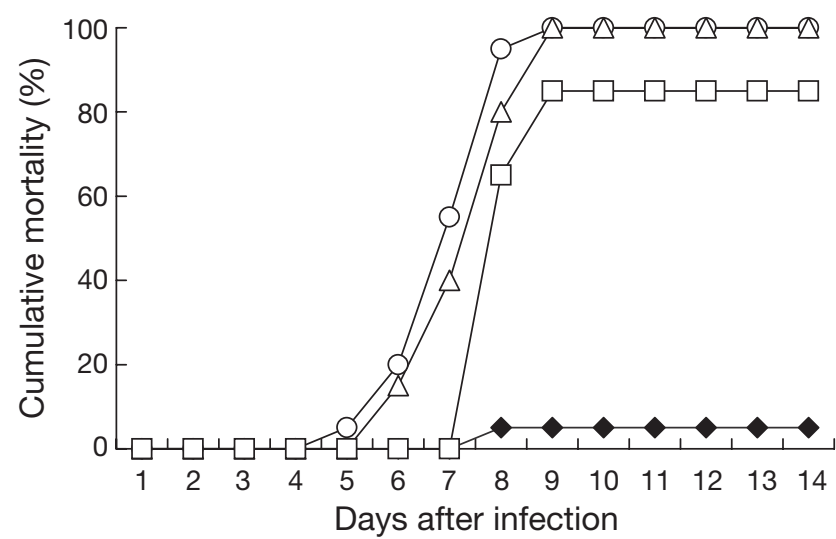

Fig. 1. Paralichthys olivaceus and Miamiensis avidus. Cumulative mortality of olive flounder groups immersion-challenged with $M$. avidus Strain YS1 at $2 \times 10^{3}(-\square-), 2 \times 10^{4}$ $\left(-\Delta^{-}\right)$and $2 \times 10^{5}$ cells ml ${ }^{-1}\left(-\mathrm{O}^{-}\right)$and control group (- -$)$

mouth, fins and dorsal area. Light microscopy of wet mount preparations showed high numbers of ciliates in ulcer lesions, gills and brain tissue. Fish started to die 5,6 and $8 \mathrm{~d}$ post-infection in the treatment concentrations of $2.0 \times 10^{5}, 2.0 \times 10^{4}$ and $2.0 \times 10^{3}$ ciliates $\mathrm{ml}^{-1}$, respectively. The cumulative mortality reached $100 \%$ in the $2.0 \times 10^{5}$ and $2.0 \times 10^{4}$ groups and $85 \%$ in the $2.0 \times 10^{3}$ group (Fig. 1).

\section{Histological examination}

Under histological examination, ciliates were found predominantly in gills, skin, skeletal muscle, fins, digestive tracts and central nervous systems of infected fish. Ciliates containing numerous erythrocytes in the cytoplasm were observed in the gills, and hemorrhagic lesions were observed in the skeletal muscle and brain. In the gills, ciliates were observed mainly in the arterioles of the lamellae, and the respiratory epithelial layer was sloughed from the basement membrane (Fig. 2A). Severe gill erosion was observed in naturally infected fish, but not in the experimentally infected groups. In addition, ciliates containing erythrocytes in the cytoplasm were present in the gill filaments and pharynx (Fig. 2B), as well as in the cornea (Fig. 2C). In the fins, hyaline cartilage was destroyed by severe hemorrhages, and necrosis of muscle fibers was observed (Fig. 2D), as were severe hemorrhages in the dermis and muscle layers (Fig. 2E). In the skin, many ciliates were found in the scale pockets, and the epidermis was sloughed or absent (Fig. 2F,G). In the stomach and intestine, the lamina propria was heavily infected by ciliates, although no obvious pathology was detected in the epithelium or muscular layers (Fig. 2H). In the central nervous system, ciliates were 

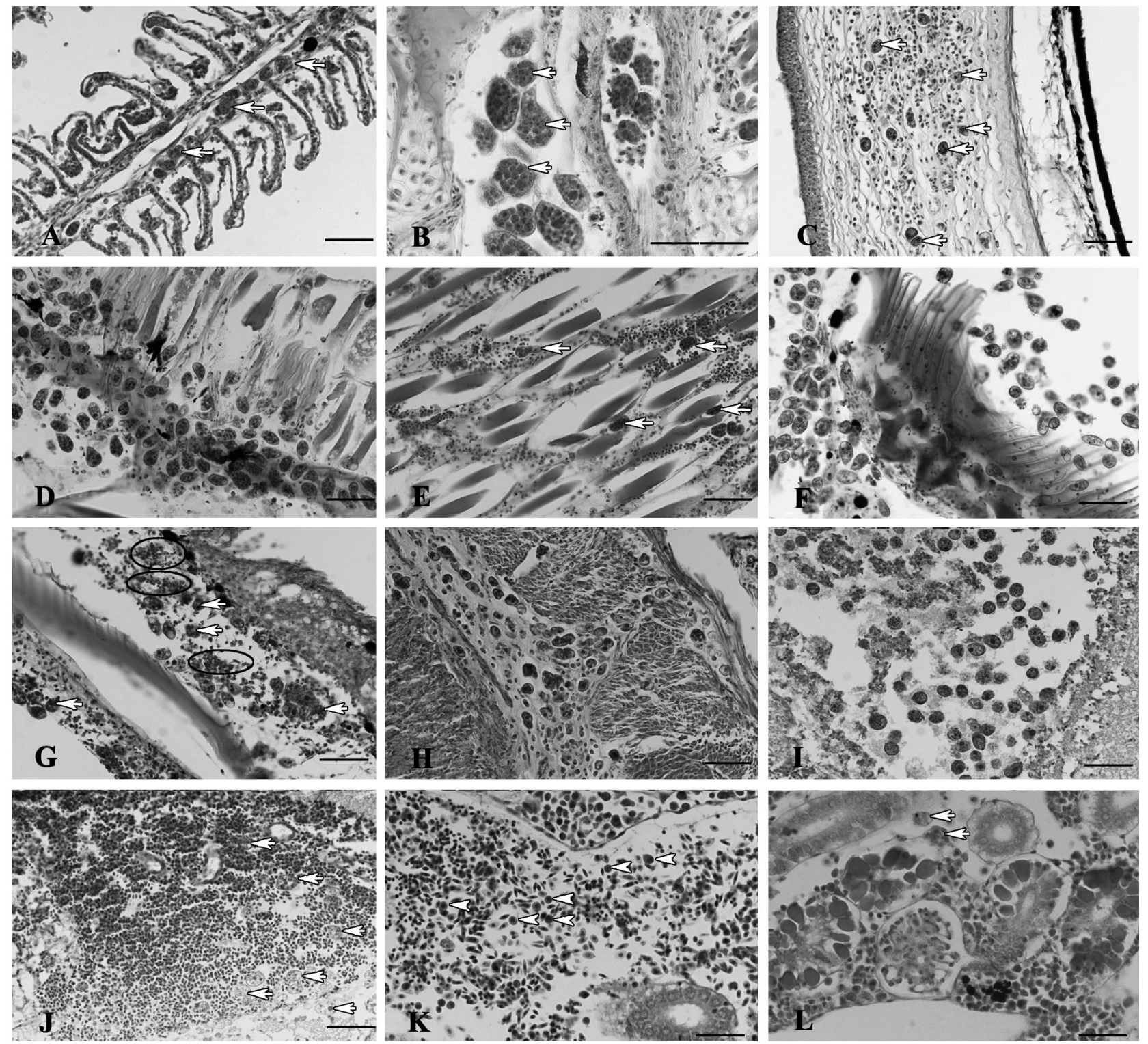

Fig. 2. Paralichthys olivaceus. Microscopic pathological changes of experimentally infected olive flounder. (A) Ciliates (arrows) in the blood vessels in gill lamellae. Respiratory epithelium is sloughed from the basement membrane. (B) Ciliates containing fish erythrocytes (arrows) in the pharynx. (C) Ciliates in the cornea of the eye. (D) Ulcerated lesion of fin with necrotized muscle fiber due to heavy ciliate infection. (E) Skeletal muscles with hemorrhages and swelling due to ciliate infection. (F) Numerous ciliates in scale pocket. (G) Ciliates (arrows) in dermis with hemorrhages (encircled areas). (H) Ciliates in lamina propria of the stomach. (I) Ciliates invading ventricle of the brain. (J) Severe hemorrhages and necrosis of the brain accompanied by ciliate infection (arrows). (K) Inflammatory cell (arrowheads) infiltrations in the kidney. (L) Ciliates (arrows) in haematopoietic tissue and hyaline droplets in kidney tubules. Scale bars $=50 \mu \mathrm{m}$

observed in the meninges, telencephalon, diencencephalon, optic lobes, cerebellum and medulla oblongata; perhaps the most significant pathology in the brain was the presence of ciliates and consequent hemorrhaging in the 4th ventricle (Fig. 2I,J). There was an increase in the number of inflammatory cells in the kidney (Fig. 2K), and hyaline droplets were observed in the renal tubules (Fig. 2L).

\section{Live observation}

Ciliates recovered from infected fish and CHSE214 cells were highly motile, robust and granular in appearance, due to the presence of numerous food vacuoles located mainly in the posterior half of the body. The ciliates contained a single translucent contractile vacuole near the posterior pole (Fig. 3A, $\mathrm{A}^{\prime}$ ). 
In the wet mounts of the gills, some ciliates contained host erythrocytes in the cytoplasm.

\section{Silver impregnation}

The ciliates were ovoid and slightly elongated in shape, pointed in the anterior position and rounded posteriorly, with a contractile vacuole and caudal cilium (Fig. 3A, A'). Their key morphometric characteristics are summarized in Table 1. Fixed and stained ciliates ranged from 21 to $37 \mu \mathrm{m}$ (mean $\pm \mathrm{SD}: 31.5 \pm 3.87$ ) in length and 11 to $28 \mu \mathrm{m}(18.5 \pm 3.04)$ in width. At the center of the body was a spherical macronucleus, $6.3 \mu \mathrm{m}$ in diameter (Fig. 3B, B'); adjacent to this was a spherical micronucleus of $1.55 \mu \mathrm{m}$ diameter. The densely arranged somatic cilia measured $5.75 \mu \mathrm{m}$ in length, and the 1 single caudal cilium in each ciliate measured, on average, $8.6 \mu \mathrm{m}$ in length. There were 13 or 14 longitudinal kineties running parallel to the body axis (Fig. $3 \mathrm{C}_{1} \mathrm{C}^{\prime}$ ), with the last kinety $(\mathrm{Kn})$ terminating about halfway along oral polykinetid 1 (Fig. 3C, $\mathrm{C}^{\prime}$ ). There was a single contractile vacuole located at the posterior end of somatic kinety 2 (Fig. 3D, D'). The morphology of the oral ciliary fields is shown in Fig. 4, with representative ciliates presented in Fig. $4 \mathrm{~A}\left(\mathrm{~A}^{\prime}\right)$ \& $\mathrm{B}\left(\mathrm{B}^{\prime}\right)$. The oral ciliary field begins, on average, $3.55 \mu \mathrm{m}$ from the anterior pole, and the length of the oral ciliary field is $12.5 \mu \mathrm{m}$. The buccal apparatus comprises a paroral membrane (PM) composed of 2 parts (PM1 and PM2) separated by a narrow gap and 3 oral polykinetids with membranelles M1, M2 and M3. PM1 (mean length: $2.9 \mu \mathrm{m}$ ) begins near the anterior end of oral polykinetid 2 , and is composed of a monokinetid. PM2 (mean length: $4.6 \mu \mathrm{m}$ ) comprises dikinetids, and curves along the oral cavity depression. The first polykinetid (M1) appears as 2 longitudinal rows of kinetosomes with 4 or 5 basal bodies, whereas the second polykinetid (M2) has 3 to 5 longitudinal rows with 4 to 6 basal bodies. The third polykinetid (M3) consists of 1 or 2 longitudinal rows with 3 to 5 basal bodies. M1, M2 and M3 were $2.15,2.60$ and $0.69 \mu \mathrm{m}$ in length, respectively. The buccal apparatus showed a high degree of structural variation: in some cases, PM1 and PM2 were discrete (Fig. 4A $\mathrm{A}^{\prime}, \mathrm{B}^{\prime}, \mathrm{C}^{\prime}, \mathrm{E}^{\prime}, \mathrm{J}^{\prime}$ ), whereas in others they formed a

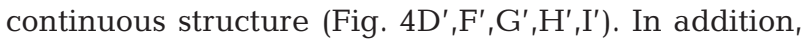
M3 was sometimes absent (Fig. $4 \mathrm{E}^{\prime}, \mathrm{F}^{\prime}, \mathrm{G}^{\prime}, \mathrm{H}^{\prime}, \mathrm{J}^{\prime}$ ); when present, it possessed 2 longitudinal rows, and 4 or 5 basal bodies were observed (Fig. 4C, $\mathrm{C}^{\prime}$ ).

\section{DISCUSSION}

Although several species of scuticociliates (e.g. Philasterides dicentrarchi, Uronema nigricans, U. marinum and Tetrahymena corliss) are known to be histophagous parasites, causing severe infections in fish (Dragesco et al. 1995, Munday et al. 1997, Imai et al. 2000), the pathogenicity remains poorly understood. Alvarez-Pellitero et al. (2004) reported histophagous scuticociliates (either Philasterides Kahl, 1931 or Miamiensis Thompson et Moewus, 1964) that were pathogenic to turbot when injected intraperitoneally. Paramá et al. (2003) attempted to infect farmed turbot with $P$. dicentrarchi via nasal, oral, rectal, branchial/dermal, intraperitoneal, periorbital and intramuscular routes, and found that the parasite was able to infect the host only by the intraperitoneal route. Additionally, immersion infection was only successful if branchial/dermal areas had been abraded prior to exposure to the parasite, leading the authors to hypothesize that $P$. dicentrarchi invades the turbot via small lesions in the skin and/or gills. In contrast, the current study demonstrated that Miamiensis avidus successfully invade into the host directly from seawater, causing high mortality. It is the first report of successful immersion infection, and we con-

clude that $M$. avidus is a strong
Fig. 3. Miamiensis avidus. Live $\left(\mathrm{A}, \mathrm{A}^{\prime}\right)$, silver carbonate $\left(\mathrm{B}, \mathrm{B}^{\prime}, \mathrm{C}, \mathrm{C}^{\prime}\right)$ and wet silver nitrate $\left(D_{1}, D^{\prime}\right)$ impregnated scuticociliate from olive flounder $\left(C, C^{\prime}\right)$. Apical view showing numbers of somatic kineties and shortened last kinety (Kn). (D, D') Caudal view showing contractile vacuole pore (VP) and cytopyge $(\mathrm{CP})$; numbers refer to somatic kineties. CC: caudal cilium; CV: contractile vacuole; Ma: macronucleus; M1 to M3: Membranelles 1 to 3; PM: paroral membrane. Scale bars $=5 \mu \mathrm{m}$ 


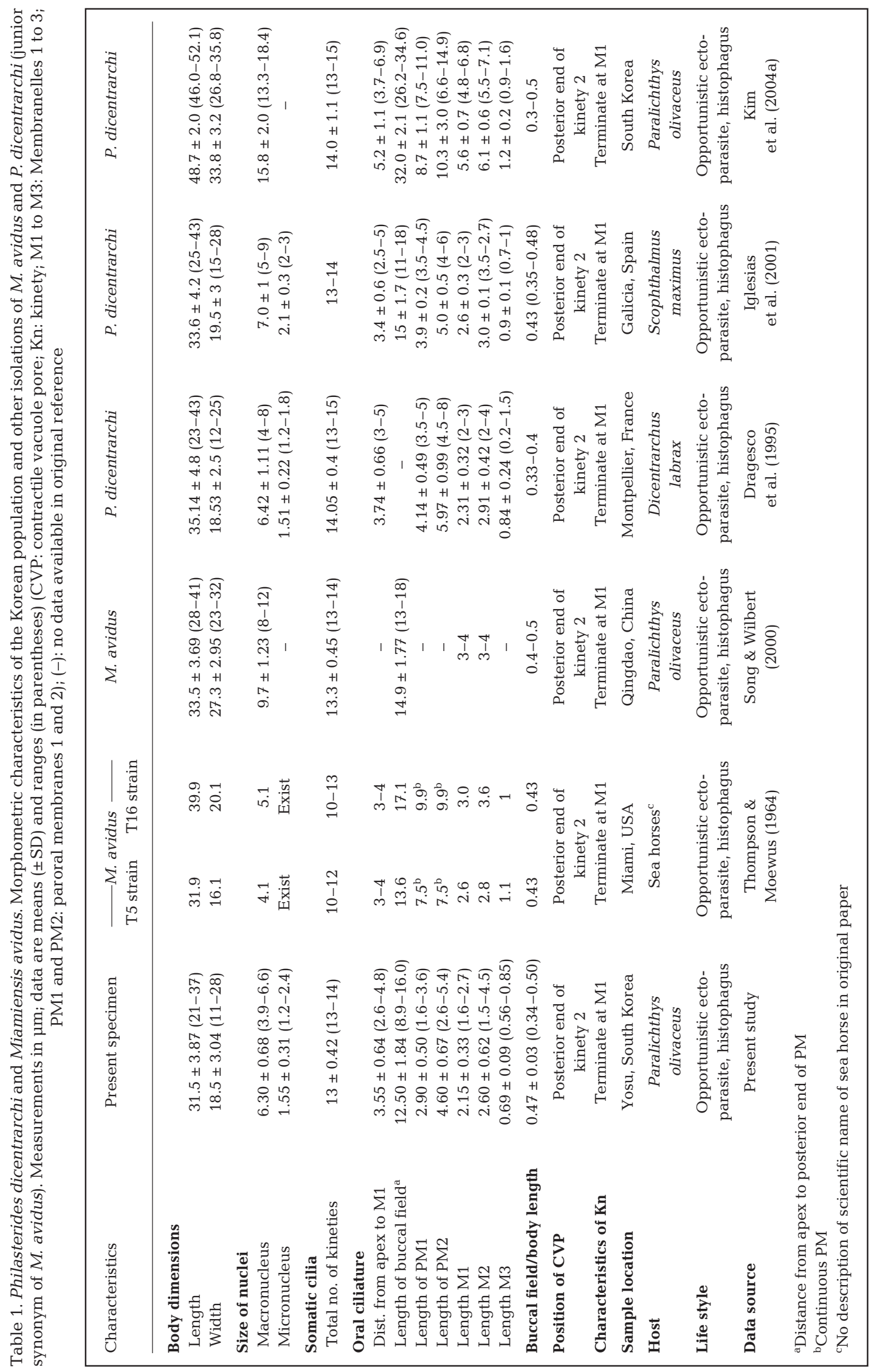



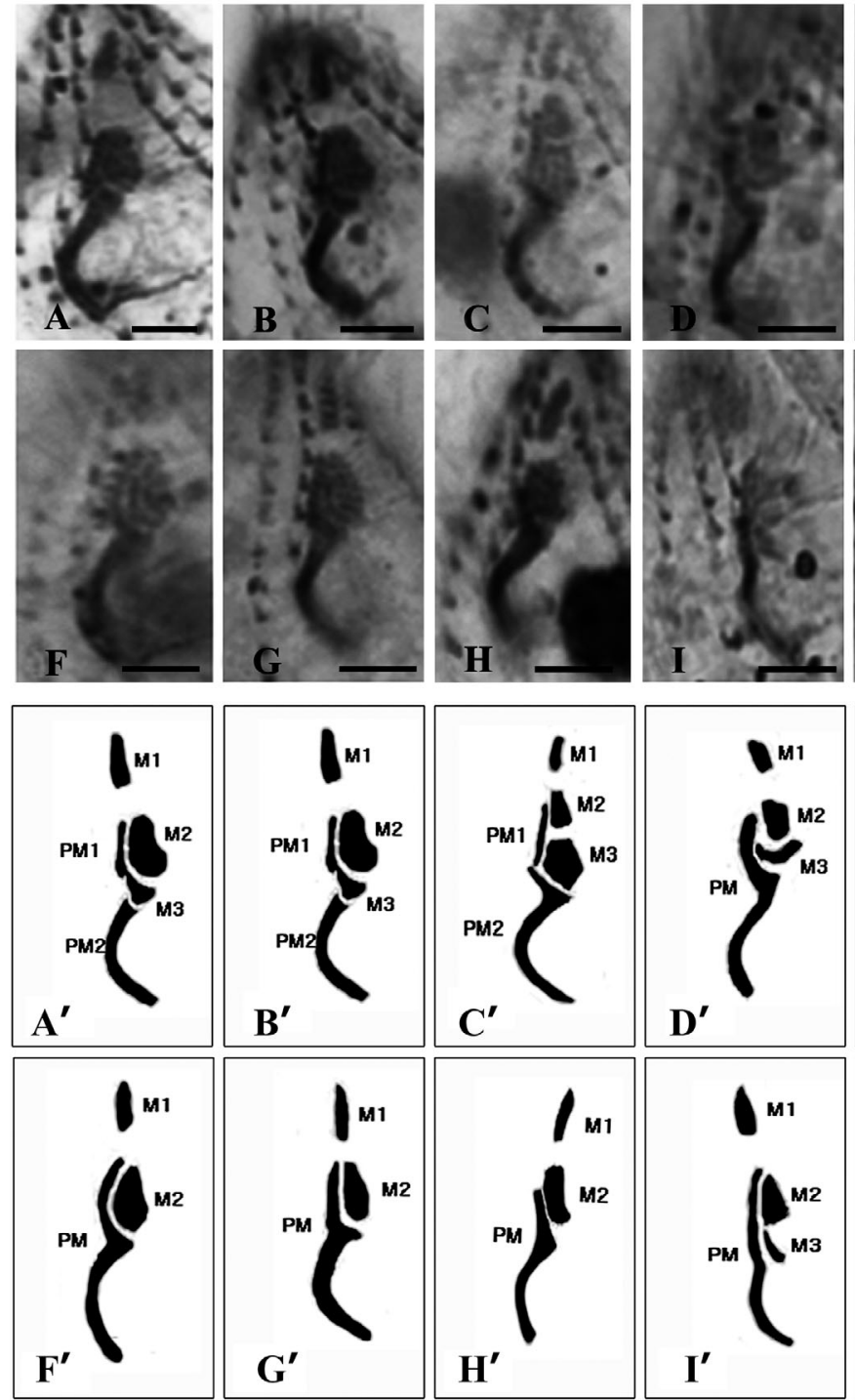

Fig. 4. Miamiensis avidus. Details of buccal apparatus of silver-carbonate-impregnated $M$. avidus. M1 to M3: Membranelles 1 to 3; PM1 and PM2: paroral membranes 1 and 2. Scale bars $=3 \mu \mathrm{m}$

pathogen that can cause primary infection. The ciliates rapidly invade and proliferate in the skin and gills, as evidenced by the large numbers found at these locations in infected fish. They then consume both host cells and body fluids, and spread to the internal organs in the absence of any additional pathogens such as secondary bacterial invaders.

Iglesias et al. (2001) found that turbot infested by Philasterides dicentrarchi exhibited very similar clinical signs to the infected olive flounder in this study, i.e. darkening of the skin, hemorrhagic skin ulcers and the presence of ciliates in muscles, gills, brain and internal organs. In addition, both $P$. dicentrarchi and Miamiensis avidus exhibited systemic invasion of
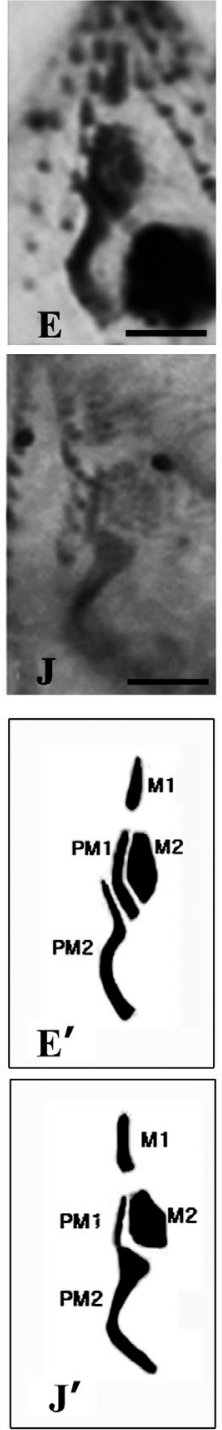

the digestive tract, liver, kidneys and gonads. As suggested by Iglesias et al. (2001), it appears that once the ciliates enter the host, they spread quickly via blood vessels and establish a systemic infection. Histological examination demonstrated the presence of ciliates in the blood vessels of gills and the ventricles of the brain; in addition, ciliates were detected in blood from the caudal vein (data not shown). It is unlikely that the ciliates invade the host via an oral route, as suggested by Paramá et al. (2003): the low pH of the stomach lumen would likely provide a sufficient barrier to infection, because $M$. avidus can only survive in a $\mathrm{pH}$ range of 5 to 10 (data not shown). In addition, the mucosal epithelium of the digestive tract was not damaged in experimentally infected fish, and ciliates were found predominantly in the highly vascular lamina propria. This also supports the idea that ciliates probably do not infect by an oral route, but mainly through the skin and/or gills, and that they spread via blood.

Flatfish such as turbot (Sterud et al. 2000, Iglesias et al. 2001, Alvarez-Pellitero et al. 2004) and olive flounder (Yoshinaga \& Nakazoe 1993, Jee et al. 2001, Kim et al. $2004 a, b)$ may be particularly predisposed to scuticociliate infection under culture conditions. Since flatfish are sedentary and utilize only the bottom of the culture tanks, individuals are often stacked 2 to 3 layers deep. Flatfish tend to aggregate, even in a bare tank, as a means of protection. Such a high density of fish, with concomitant skin-to-skin contact, may facilitate transmission of parasites among the population, resulting in high infection and mortality rates.

Based on morphological characteristics, we identified the scuticociliate detected in the present study as Miamiensis avidus Thompson \& Moewus, 1964, a facultative parasite isolated originally from sea horses (Thompson \& Moewus 1964). The species has also been found as a histophagous ectoparasite in olive flounder in the Weifang and Shandong provinces of China (Song \& Wilbert 2000). The aforementioned 
authors reported that Philasterides dicentrarchi, described by Dragesco et al. (1995) as a histophagous parasite of sea bass, is possibly an extreme population of $M$. avidus, and proposed $P$. dicentrarchi as a junior synonym of $M$. avidus. In the present study, we confirmed that $P$. dicentrarchi and $M$. avidus are conspecific based on careful morphological descriptions and a wide range of reference comparisons. In addition, our study exhibited that morphology of the PM (PM1, PM2) and M1, M2 and M3 cannot be used as a consistent key for identification of the species. Dragesco et al. (1995) distinguished between $P$. dicentrarchi and $M$. avidus (Thompson \& Moewus 1964) stating that $M$. avidus had no caudal cilium and that its buccal field was broader than that of $P$. dicentrarchi. However, the original paper by Thompson \& Moewus (1964) described a caudal cilium. In addition, although $P$. dicentrarchi was initially reported to have a lower buccal field to body length ratio (0.33 to 0.4; Dragesco et al. 1995) than M. avidus (0.43, Thompson \& Moewus 1964), subsequent reports showed the former to possess a ratio in the range of 0.35 to 0.48 (Iglesias et al. 2001) and 0.3 to 0.5 (Kim et al. 2004a), values that are within the originally reported range of $M$. avidus. The ratios for $M$. avidus in our study and that of a Chinese population (Song \& Wilbert 2000) ranged from 0.34 to 0.57 (mean: 0.47 ) and 0.4 to 0.5 , respectively. We believe that the observed variation between $M$. avidus and $P$. dicentrarchi reflects intraspecific variation, and is not a reliable criterion upon which to separate species. As regards the PM, Thompson \& Moewus (1964) described a continuous PM of $7.5 \mu \mathrm{m}$ length; however, they also reported that some cells possess a narrow gap between the anterior and posterior portions of the PM. Other studies have reported discrete PM1 and PM2 (Dragesco et al. 1995, Song \& Wilbert 2000, Iglesias et al. 2001, Kim et al. 2004a). In the current study, both PM types (continuous and discontinuous) were observed, and the PM length of $7.5 \mu \mathrm{m}$ was similar to that reported by Thompson \& Moewus (1964). Although all other reports have described the existence of M3, M3 was the most variable structure within the buccal apparatus in the present study: a typical cell possessed an M3 with 1 or 2 longitudinal rows and 3 to 5 basal bodies; in almost one-third of the cells, the M3 was completely absent.

SSU rRNA sequences have been used to identify and compare distantly related organisms (Hillis \& Dixon 1991, Hirt et al. 1995). In a previous study, we deposited a 1759 bp SSU rRNA sequence for Miamiensis avidus in GenBank under Accession Number AY550080 (Jung et al. 2005). Subsequently, the SSU rRNA sequences of Philasterides dicentrarchi became available (GenBank Accession Number AY642280), and the 2 species were found to differ by only 2 nucleotides (99.83\% homology). Therefore, based on the morphological characteristics and SSU rRNA sequences, we conclude that $M$. avidus Thompson \& Moewus, 1964 and P. dicentrarchi Dragesco et al. 1995 are synonymous.

Before clinical countermeasures can be implemented against scuticociliates, the infection mechanisms of Miamiensis avidus, as well as the defense mechanisms of the host, need to be elucidated. In addition, ecological study of the ciliates, both under aquaculture and open-water conditions, may provide pointers to preventing infection.

Acknowledgements. This work was supported by Grant No. R1-2003-000-10604-0 from the Basic Research Program of the Korean Science \& Engineering Foundation. We thank Professor W. Song, Laboratory of Protozoology, Ocean University of China, for helpful discussions.

\section{LITERATURE CITED}

Alvarez-Pellitero P, Palenzuela O, Padrós F, Sitjà-Bobadilla A, Riaza A, Silva R, Arán J (2004) Histophagous scuticociliatids (Ciliophora) parasitizing turbot Scophthalmus maximus: morphology, in vitro culture and virulence. Folia Parasitol 51:177-187

Dragesco A, Dragesco J, Coste F, Gasc C, Romestand B, Raymond J, Bouix G (1995) Philasterides dicentrarchi n. sp. (Ciliophora, Scuticociliatida), a histophagous opportunistic parasite of Dicentrachus labrax (Linnaeus, 1758), a reared marine fish. Eur J Protistol 31:327-340

Foissner W (1991) Basic light and scanning electron microscopic methods for taxonomic studies of ciliated protozoa. Eur J Protistol 27:313-330

Hillis DM, Dixon MT (1991) Ribosomal DNA: molecular evolution and phylogenetic inference. Q Rev Biol 66: 411-446

Hirt RT, Dyal PL, Wilkinson M, Finlay BJ, Roberts DM, Embley TM (1995) Phylogenetic relationship among karyorelictids and heterotrichs inferred from small subunit rRNA sequences: resolution at the base of the ciliate tree. Mol Phylogenet Evol 4:77-87

Iglesias R, Paramá A, Alvarez MF, Leiro J, Fernández J, Sanmartin ML (2001) Philasterides dicentrarchi (Ciliophora, Scuticociliatida) as the causative agent of scuticociliatosis in farmed turbot Scophthalmus maximus in Galicia (NW Spain). Dis Aquat Org 46:47-55

Imai S, Tsurimaki S, Goto E, Wakita K, Hatai K (2000) Tetrahymena infection in guppy Poecilia reticulata. Fish Pathol 35:67-72

Jee BY, Kim YC, Park MS (2001) Morphology and biology of parasite responsible for scuticociliatosis of cultured olive flounder Paralichthys olivaceus. Dis Aquat Org 47:49-55

Jung SJ, Kitamura SI, Song JY, Joung IY, Oh MJ (2005) Complete small subunit rRNA gene sequence of the scuticociliate Miamiensis avidus pathogenic to olive flounder Paralichthys olivaceus. Dis Aquat Org 64:159-162

Kim SM, Cho JB, Lee EH, Kwon SR, Kim SK, Nam YK, Kim $\mathrm{KH}$ (2004a) Occurrence of scuticociliatosis in olive flounder Paralichthys olivaceus by Phiasterides dicentrarchi (Ciliophora: Scuticociliatida). Dis Aquat Org 62:233-238 
Kim SM, Cho JB, Lee EH, Kwon SR, Kim SK, Nam YK, Kim KH (2004b) Pseudocohnilembus persalinus (Ciliophora: Scuticociitida) is an additional species causing scuticociliatosis in olive flounder Paralichthys olivaceus. Dis Aquat Org 62:239-244

Munday BL, O'Donoghue PJ, Watts M, Rough K, Hawkesford $\mathrm{T}$ (1997) Fatal encephalitis due to the scuticociliata Uronema nigricans in sea-caged, southern bluefin tuna Thunnus maccoyii. Dis Aquat Org 30:17-25

Paramá A, Iglesias R, Álvarez MF, Leiro J, Aja C, Sanmartín ML (2003) Philasterides dicentrarchi (Ciliophora, Scuticociliatida): experimental infection and possible routes of entry in farmed turbot (Scophthalmus maximus). Aquaculture 217:73-80

Editorial responsibility: Dieter Steinhagen,

Hannover, Germany
Song W, Wilbert N (2000) Redefinition and redescription of some marine scuticociliates from China, with report of a new species, Metanophrys sinensis nov. sp. (Ciliophora, Scuticociliatida). Zool Anz 239:45-74

Sterud E, Hansen MK, Mo TA (2000) Systemic infection with Uronema-like ciliates in farmed turbot Scophthalmus maximus (L.). J Fish Dis 23:33-37

Thompson JC, Moewus L (1964) Miamiensis avidus n. g., n. sp., a marine facultative parasite in the ciliate order Hymenostomatida. J Protozool 11:378-381

Yoshinaga T, Nakazoe J (1993) Isolation and in vitro cultivation of an unidentified ciliate causing scuticociliatosis in Japanese flounder (Paralichthys olivaceus). Gyobyo Kenkyu 28:131-134

Submitted: April 3, 2006; Accepted: September 20, 2006 Proofs received from author(s): January 10, 2007 